\title{
Differences between men and women with nonradiographic axial spondyloarthritis: clinical characteristics and treatment effectiveness in a real-life prospective cohort
}

Regula Neuenschwander ${ }^{1}$, Monika Hebeisen ${ }^{1,2}$, Raphael Micheroli ${ }^{1}$, Kristina Bürki ${ }^{1}$, Pascale Exer ${ }^{3}$, Karin Niedermann ${ }^{4}$, Michael J. Nissen ${ }^{5}$, Almut Scherer ${ }^{2}$ and Adrian Ciurea ${ }^{1 *}$ (D)

\begin{abstract}
Background: Sex differences with regard to clinical manifestations and response to tumor necrosis factor inhibitors (TNFi) have been delineated for the radiographic form of axial spondyloarthritis (axSpA). More limited evidence for a differential effectiveness of treatment in genders exists for the nonradiographic disease state (nr-axSpA). The aim of the study was to compare demographics, clinical parameters, and response to TNFi in women versus men with nr-axSpA.

Methods: We compared disease characteristics of 264 women and 231 men with nr-axSpA at inclusion in the prospective Swiss Clinical Quality Management Cohort. Response to a first TNFi was assessed in 85 women and 78 men without diagnosed co-morbid fibromyalgia. The primary outcome was the proportion of patients achieving the $40 \%$ improvement in the Assessment of SpondyloArthritis international Society criteria (ASAS40) at 1 year. Additional response outcomes were evaluated as secondary outcomes. Patients having discontinued TNFi were considered non-responders. Logistic regression analyses were adjusted for baseline differences, which might potentially mediate the effect of sex on treatment response.

Results: Compared to men, women had a longer diagnostic delay, a higher level of perceived disease activity, and more enthesitis and were in a lower percentage HLA-B27 positive. An ASAS40 response was achieved by $17 \%$ of women and $38 \%$ of men (OR 0.34; $95 \% \mathrm{Cl} 0.12,0.93 ; p=0.02)$. A significantly lower response rate in women was confirmed in the adjusted analysis (OR 0.19; $95 \% \mathrm{Cl} 0.05,0.62 ; p=0.009)$ as well as for the other outcomes assessed.
\end{abstract}

Conclusion: Despite only few sex differences in patient characteristics in nr-axSpA, response rates to TNFi are significantly lower in women than in men.

Keywords: Axial spondyloarthritis, Nonradiographic axial spondyloarthritis, Gender, TNF inhibition

\footnotetext{
* Correspondence: adrian.ciurea@usz.ch

'Department of Rheumatology, Zurich University Hospital, Gloriastrasse 25, CH-8091 Zurich, Switzerland

Full list of author information is available at the end of the article
}

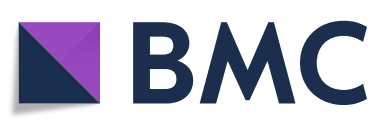

( ) The Author(s). 2020 Open Access This article is licensed under a Creative Commons Attribution 4.0 International License, which permits use, sharing, adaptation, distribution and reproduction in any medium or format, as long as you give appropriate credit to the original author(s) and the source, provide a link to the Creative Commons licence, and indicate if changes were made. The images or other third party material in this article are included in the article's Creative Commons licence, unless indicated otherwise in a credit line to the material. If material is not included in the article's Creative Commons licence and your intended use is not permitted by statutory regulation or exceeds the permitted use, you will need to obtain permission directly from the copyright holder. To view a copy of this licence, visit http://creativecommons.org/licenses/by/4.0/. The Creative Commons Public Domain Dedication waiver (http://creativecommons.org/publicdomain/zero/1.0/) applies to the data made available in this article, unless otherwise stated in a credit line to the data. 


\section{Background}

With the introduction of the Assessment of SpondyloArthritis international Society (ASAS) classification criteria [1], patients with axial spondyloarthritis (axSpA) can be classified as having radiographic or nonradiographic disease ( $r$-axSpA vs. nr-axSpA), depending on the presence or absence of definite radiographic sacroiliac changes according to the modified New York criteria [2], respectively [3]. There is ample evidence that, from a clinical point of view, patients with nr-axSpA have a similar disease burden when compared with patients with $r$-axSpA [4-9]. The latter is, however, associated with a higher propensity to osteoproliferation potentially leading to spinal ankylosis and a greater impairment of spinal mobility $[10,11]$. While a male predominance is found in $\mathrm{r}$-axSpA, an equal male to female distribution has repeatedly been reported for $\mathrm{nr}$-axSpA. Some important differences in clinical manifestations and response to treatment between the sexes have been delineated for the radiographic disease form [12-19]. In comparison to men, women with $\mathrm{r}$-axSpA present with higher self-reported disease activity and functional impairment, a lower quality of life, less severe spinal radiographic changes, and more peripheral disease (arthritis and enthesitis). Objective markers of inflammation, such as elevated Creactive protein (CRP) levels and magnetic resonance imaging (MRI) inflammation of the axial skeleton are more often found in men. It remains unclear, whether comparable differences between the sexes exist for nraxSpA. Indeed, available data on gender differences in nr-axSpA is limited to subgroups (e.g., clinical arm of the ASAS classification criteria) [20]. Following the demonstration of response to tumor necrosis factor inhibitors (TNFi) also in active nr-axSpA following an inadequate response to nonsteroidal anti-inflammatory drugs (NSAIDs) [21-24], this subgroup of patients has been included in recent recommendations for the treatment of axSpA with biologic disease-modifying antirheumatic drugs (bDMARDs) $[25,26]$. There exists some evidence for a differential effectiveness of treatment in female versus male patients with nr-axSpA $[8,27]$. The aim of this study was to compare male and female patients classified as having nr-axSpA with regard to demographics, clinical manifestations and response to tumor necrosis factor inhibitors (TNFi) in a large national observational cohort.

\section{Patients and methods}

\section{Study population}

Patients with a clinical diagnosis of axSpA in the Swiss Clinical Quality Management (SCQM) cohort [6] were included in the current study if they met the following conditions: (a) fulfillment of the Assessment of
SpondyloArthritis international Society (ASAS) classification criteria for axSpA [1] and (b) lack of definite radiographic sacroiliac changes according to the modified New York criteria [2]. The latter was assessed on collected radiographs of the pelvis, which were centrally digitized, and independently scored in a blinded matter by 2 rotating members of the SCQM axSpA scientific board (a total of 6 calibrated readers) [6]. Discrepancies between 2 readers in the evaluation of the sacroiliac joints were solved by consensus. Data on sacroiliac or spinal magnetic resonance imaging (MRI) scan positivity for inflammation was entered in the online database by the treating rheumatologist at each visit (expert opinion of local rheumatologist or radiologist; no central MRI scoring performed, as MRI scans were not collected).

Clinical evaluations were recommended at inclusion in the cohort, at yearly intervals thereafter, as well as at treatment changes and were performed according to the recommendations of ASAS [28]. Enthesitis was assessed with the Maastricht Ankylosing Spondylitis Enthesitis Score (MASES), modified to include the proximal insertion of the plantar fasciae. Rheumatologists indicate the presence of enthesitis by clicking on the specified enthesitis location on a homunculus shown from front and back. The rheumatologist is reminded of the intensity of the pressure to test for enthesitis with a written note adjacent to the homunculus: "thumb pressure of approximately $4 \mathrm{~kg}$, corresponding to the pressure leading to discoloration of a third of the thumbnail."

The diagnosis of concurrent fibromyalgia was based on the expert opinion of the treating rheumatologist and reported through a comorbidity questionnaire. The rheumatologist is automatically led through the comorbidity questionnaire in the online database at the time of reporting the results of the clinical examination to ensure systematic completion of the form. The proportion of the population with available data on comorbidities was $62 \%$. The fulfillment of classification criteria for fibromyalgia was not required and no standardized fibromyalgia questionnaire was used.

Data on patients recruited into SCQM from January 2005 to November 2018 were available for the current analysis. The Ethics committee of the Canton of Zurich (KEK-ZH-Nr. 2014-0439) approved the study and written informed consent was obtained from all patients prior to inclusion into SCQM.

\section{Treatment effectiveness}

Assessment of response to treatment with a first TNFi was analyzed in patients with available information on disease activity at start of treatment, as well as with an available outcome at 1 year ( \pm 6 months). Patients with concomitant fibromyalgia were excluded from the analyses if this feature was reported either at baseline or at 
any time-point during follow-up. Given the fact the patients treated with biologics are preferentially included in SCQM, we expected a lower proportion of patients with fibromyalgia in comparison to other studies, assuming that rheumatologists might be reluctant to install biologics in axSpA patients diagnosed with concurrent fibromyalgia.

Response was either assessed in patients still on treatment at this time-point (completer analysis) or in all patients-with those having discontinued treatment in the meantime being considered non-responders (response/tolerance analysis) [18]. The achievement of the $40 \%$ improvement ASAS criteria (ASAS40) was considered as the primary outcome. We also analyzed additional response rates: ASAS20 response criteria, the proportion of patients achieving an Ankylosing Spondylitis Disease Activity Score (ASDAS) $<2.1$ or an ASDAS $<1.3$ (remission), as well as a clinically important and major improvements in ASDAS. It is important to note that the majority of TNFi (adalimumab, etanercept, golimumab and infliximab) are approved for the treatment of "Bechterew's" disease after inadequate response to conventional treatment in Switzerland, with no differentiation being made in the label between the radiographic and the nonradiographic disease form. The label for certolizumab-pegol differs in this respect. It is approved in Switzerland for the treatment of severe active axial spondyloarthritis, including patients with severe active ankylosing spondylitis as well as severe active $n r-a x S p A$, if the patients have inadequately responded to conventional treatment or had experienced adverse events to nonsteroidal anti-rheumatic drugs. Moreover, patients with severe active $n r-a x S p A$ requiring certolizumab-pegol should present with objective signs of inflammation (either on MRI or an elevated C-reactive protein (CRP)).

\section{Statistical analyses}

Comparisons between baseline characteristics in women and men were performed using the Fisher's exact test for categorical variables and the Mann-Whitney $U$ test for continuous variables. The Fisher's exact test was used to assess the significance of differences in response rates between genders. An adjusted odds ratio for different response criteria was estimated through logistic regression analysis. The following variables were included in the models as they differed between men and women at start of treatment and could potentially be mediators of the effect of sex on treatment response: diagnostic delay, degree of enthesitis, the level of the Bath Ankylosing Spondylits Disease Activity Index (BASDAI), and the body mass index (BMI). Drug retention was assessed with Kaplan-Meier plots and differences in retention rates were analyzed with the log-rank test. All tests were 2-sided (significance level set at 0.05 ). $\mathrm{R}$ statistical software was utilized for all analyses.

\section{Results \\ Baseline characteristics}

From a total of 1818 patients fulfilling the ASAS classification criteria with an available baseline pelvis radiograph, 495 patients presented without definite sacroiliac changes according to central scoring and were included as nr-axSpA in the current study (231 men and 264 women). Baseline characteristics of these patients are shown in Table 1 (A). Women were slightly older at inclusion, which was mainly due to a significantly longer diagnostic delay, as the age at symptom onset was comparable between the genders. In comparison to men, a slightly lower proportion of women was HLA-B27 positive $(67.0 \%$ vs. $76.5 \%, p=0.03)$. Mean \pm SD disease activity as assessed by the BASDAI was higher in women than in men $(5.3 \pm 2.1$ vs. $4.6 \pm 2.2, p=0.003)$. CRP levels and the proportion of patients with elevated CRP were comparable between the sexes, as was the ASDAS. Moreover, there were no differences with regards to impairment of physical function (BASFI), spinal mobility (BASMI), and of quality of life (EQ-5D). Regarding peripheral manifestations, the proportion of men and women with peripheral arthritis and dactylitis was comparable. However, female nr-axSpA patients presented more often with peripheral enthesitis and with a higher MASES. The proportion of patients with concomitant clinically diagnosed fibromyalgia was higher in women than in men $(13.1 \%$ vs. $2.7 \%$, $p<0.001)$. After excluding patients with diagnosed concurrent fibromyalgia from the analyses, remaining gender differences in BASDAI were mainly due to fatigue and enthesitis, both more prominent in women than in men (Table 1 (B)). Further comparisons did not reveal any sex differences with regards to extraskeletal manifestations (uveitis, psoriasis, or inflammatory bowel disease), smoking status, education, and work absenteeism. The only additional difference between the sexes concerned the BMI (24.1 vs. 25.6 on average for women and men, respectively).

\section{Response to TNFi treatment}

Treatment response was investigated in $\mathrm{nr}-\mathrm{axSpA}$ patients without concomitant fibromyalgia. A first TNFi was initiated in 163 patients (Table 2). Corresponding to sex differences seen in the whole nr-axSpA cohort, women starting treatment had a longer diagnostic delay, higher BASDAI and MASES, and a lower BMI in comparison to men. The proportion of women initiating TNFi at an ASDAS level > 2.1 was $96.2 \%$, while it was only $83.9 \%$ in men $(p=0.02)$. A follow-up visit at 1 year to assess treatment response was available in 120 
Table 1 Characteristics of all patients classified as having nonradiographic axial spondyloarthritis at inclusion in SCQM

\begin{tabular}{|c|c|c|c|c|c|c|c|c|}
\hline \multirow[t]{2}{*}{ Parameter } & \multicolumn{4}{|c|}{ A. All nr-axSpA patients } & \multicolumn{4}{|c|}{$\begin{array}{l}\text { B. All nr-axSpA patients excluding patients with co- } \\
\text { morbid FM }\end{array}$} \\
\hline & $N, 495$ & $\begin{array}{l}\text { Men, } \\
N=231\end{array}$ & $\begin{array}{l}\text { Women, } \\
N=264\end{array}$ & $p$ & $N, 470$ & $\begin{array}{l}\text { Men, } \\
N=227\end{array}$ & $\begin{array}{l}\text { Women, } \\
N=243\end{array}$ & $p$ \\
\hline Age, years & 495 & $36.6(10.9)$ & $38.2(10.7)$ & 0.09 & 470 & $36.4(10.9)$ & $38.1(10.7)$ & 0.09 \\
\hline Age at symptom onset, years & 481 & $28.3(8.4)$ & $28.7(9.1)$ & 0.65 & 456 & $28.2(8.4)$ & $28.6(9.0)$ & 0.65 \\
\hline Symptom duration, years & 481 & $8.3(9.2)$ & $9.6(9.8)$ & 0.10 & 456 & $8.2(9.2)$ & $9.5(9.8)$ & 0.12 \\
\hline Diagnostic delay, years & 480 & $4.7(7.6)$ & $6.0(7.8)$ & 0.005 & 455 & $4.7(7.5)$ & $6.0(7.8)$ & 0.01 \\
\hline HLA-B27 positive, $\%$ & 453 & 76.5 & 67.0 & 0.03 & 430 & 77.0 & 68.2 & 0.05 \\
\hline Positive family history for spondyloarthritis, \% & 417 & 32.0 & 40.5 & 0.08 & 393 & 32.1 & 42.0 & 0.05 \\
\hline Prior sacroiliitis on MRI, \% & 477 & 52.9 & 58.7 & 0.23 & 453 & 53.9 & 58.5 & 0.34 \\
\hline BASDAI & 430 & $4.6(2.2)$ & $5.3(2.1)$ & 0.003 & 412 & $4.6(2.2)$ & $5.1(2.1)$ & 0.02 \\
\hline - BASDAI 1 (fatigue) & 436 & $4.7(2.8)$ & $6.0(2.4)$ & $<0.001$ & 418 & $4.7(2.8)$ & $5.9(2.4)$ & $<0.001$ \\
\hline - BASDAI 2 (back pain) & 436 & $5.9(2.7)$ & $6.5(2.5)$ & 0.03 & 418 & $5.9(2.7)$ & $6.3(2.5)$ & 0.10 \\
\hline - BASDAI 3 (joint pain/swelling) & 435 & $3.6(3.1)$ & $4.2(3.1)$ & 0.04 & 417 & $3.6(3.1)$ & $4.1(3.1)$ & 0.07 \\
\hline - BASDAI 4 (enthesitis) & 433 & $4.2(3.3)$ & $5.0(3.1)$ & 0.02 & 415 & $4.2(3.3)$ & $4.8(3.0)$ & 0.04 \\
\hline - BASDAI 5 (intensity of morning stiffness) & 434 & $5.2(3.0)$ & $5.4(3.1)$ & 0.65 & 416 & $5.3(3.0)$ & $5.2(3.1)$ & 0.96 \\
\hline - BASDAI 6 (duration of morning stiffness) & 433 & $4.0(2.9)$ & $4.1(2.9)$ & 0.68 & 415 & $4.0(2.9)$ & $4.0(2.9)$ & 0.99 \\
\hline Physician Global Assessment & 481 & $3.7(2.2)$ & $3.8(2.0)$ & 0.49 & 412 & $3.7(2.2)$ & $3.7(2.0)$ & 0.86 \\
\hline Patient Global Assessment & 430 & $5.3(2.9)$ & $5.6(2.8)$ & 0.27 & 412 & $5.3(2.9)$ & $5.5(2.8)$ & 0.54 \\
\hline ASDAS & 402 & $2.9(1.0)$ & $2.9(0.9)$ & 0.23 & 386 & $2.9(1.0)$ & $2.9(0.9)$ & 0.49 \\
\hline CRP (mg/l), median (IQR) & 463 & $4.0(1.0 ; 8.0)$ & $4.0(2.0 ; 8.0)$ & 0.86 & 441 & $4.0(1.1 ; 8.0)$ & $4.0(2.0 ; 8.0)$ & 0.96 \\
\hline Elevated CRP, \% & 459 & 26.5 & 26.6 & 1.00 & 437 & 26.5 & 26.1 & 1.00 \\
\hline BASFI & 435 & $2.8(2.4)$ & $3.1(2.5)$ & 0.16 & 416 & $2.8(2.4)$ & $2.9(2.4)$ & 0.54 \\
\hline BASMI & 473 & $1.3(1.4)$ & $1.3(1.3)$ & 0.98 & 449 & $1.4(1.4)$ & $1.3(1.2)$ & 0.72 \\
\hline EQ-5D & 431 & $61.4(22.5)$ & $59.7(20.1)$ & 0.34 & 412 & $61.3(22.6)$ & $61.2(19.4)$ & 0.78 \\
\hline IBP according to ASAS, \% & 462 & 80.5 & 77.3 & 0.43 & 437 & 80.6 & 77.0 & 0.41 \\
\hline Spinal MRI inflammation, \% & 476 & 26.9 & 24.9 & 0.67 & 452 & 26.9 & 23.6 & 0.45 \\
\hline Spinal radiographic changes, $\%$ & 476 & 6.3 & 3.6 & 0.20 & 452 & 5.9 & 3.0 & 0.17 \\
\hline Current peripheral arthritis,\% & 489 & 35.8 & 39.2 & 0.46 & 464 & 36.0 & 38.9 & 0.57 \\
\hline Number of swollen joints & 481 & $0.7(1.9)$ & $0.9(2.3)$ & 0.38 & 457 & $0.7(1.9)$ & $0.7(1.8)$ & 0.54 \\
\hline Current enthesitis, \% & 483 & 64.0 & 79.6 & $<0.001$ & 459 & 63.8 & 78.3 & $<0.001$ \\
\hline Modified MASES & 481 & $1.9(2.5)$ & $3.2(3.4)$ & $<0.001$ & 457 & $1.8(2.5)$ & $2.9(3.1)$ & $<0.001$ \\
\hline Co-morbid fibromyalgia, \% & 307 & 2.7 & 13.1 & $<0.001$ & - & - & - & - \\
\hline Dactylitis ever, \% & 492 & 10.9 & 11.4 & 0.89 & 468 & 10.6 & 12.0 & 0.66 \\
\hline Uveitis ever, \% & 434 & 18.1 & 13.1 & 0.18 & 410 & 18.4 & 12.9 & 0.14 \\
\hline Psoriasis ever, \% & 373 & 9.1 & 9.1 & 1.00 & 351 & 9.3 & 8.4 & 0.85 \\
\hline Inflammatory bowel disease ever, \% & 427 & 6.0 & 7.9 & 0.46 & 403 & 5.6 & 8.2 & 0.33 \\
\hline Taking NSAIDs, \% & 471 & 87.3 & 90.4 & 0.31 & 447 & 87.6 & 89.6 & 0.55 \\
\hline Taking methotrexate, \% & 495 & 5.2 & 10.2 & 0.04 & 470 & 5.3 & 9.9 & 0.08 \\
\hline Taking sulfasalazine, \% & 495 & 4.8 & 6.1 & 0.56 & 470 & 4.8 & 6.2 & 0.55 \\
\hline Taking TNFi, \% & 495 & 14.7 & 15.5 & 0.90 & 470 & 14.5 & 15.2 & 0.90 \\
\hline Ever TNFi, \% & 495 & 68.0 & 72.0 & 0.78 & 470 & 67.4 & 70.8 & 0.80 \\
\hline Current smoking, \% & 432 & 32.0 & 30.2 & 0.75 & 413 & 32.0 & 28.3 & 0.45 \\
\hline Body mass index & 483 & $25.7(3.9)$ & $24.3(4.5)$ & $<0.001$ & 458 & $25.6(3.9)$ & $24.1(4.2)$ & $<0.001$ \\
\hline Education, \% & 462 & & & 0.46 & 440 & & & 0.52 \\
\hline
\end{tabular}


Table 1 Characteristics of all patients classified as having nonradiographic axial spondyloarthritis at inclusion in SCQM (Continued)

\begin{tabular}{|c|c|c|c|c|c|c|c|c|}
\hline \multirow[t]{2}{*}{ Parameter } & \multicolumn{4}{|c|}{ A. All nr-axSpA patients } & \multicolumn{4}{|c|}{$\begin{array}{l}\text { B. All nr-axSpA patients excluding patients with co- } \\
\text { morbid FM }\end{array}$} \\
\hline & $N, 495$ & $\begin{array}{l}\text { Men, } \\
N=231\end{array}$ & $\begin{array}{l}\text { Women, } \\
N=264\end{array}$ & $p$ & $N, 470$ & $\begin{array}{l}\text { Men, } \\
N=227\end{array}$ & $\begin{array}{l}\text { Women, } \\
N=\mathbf{2 4 3}\end{array}$ & $p$ \\
\hline - Compulsory & & 15.8 & 19.8 & & & 15.2 & 18.3 & \\
\hline - Vocational & & 56.7 & 51.8 & & & 57.4 & 52.4 & \\
\hline - University & & 27.4 & 28.3 & & & 27.5 & 29.3 & \\
\hline Absenteeism within last year, \% & 389 & 53.9 & 44.0 & 0.12 & 372 & 53.9 & 43.2 & 0.10 \\
\hline
\end{tabular}

All patients with nr-axSpA are presented in A, while patients with co-morbid fibromyalgia are excluded in B. Except where indicated otherwise, values are the mean (SD). Data in bold are statistically significant. ASAS Assessment of SpondyloArthritis international Society, ASDAS Ankylosing Spondylitis Disease Activity Score, BASDAI Bath Ankylosing Spondylitis Disease Activity Index, BASFI Bath Ankylosing Spondylitis Functional Index, BASMI Bath Ankylosing Spondylitis Metrology Index, CRP C-reactive protein, EQ-5D EuroQol 5-domains, FM fibromyalgia, HLA-B27 human leucocyte antigen B27, IBP inflammatory back pain, MASES Maastricht Ankylosing Spondylitis Enthesitis Score, modification refers to the inclusion of the plantar fascia in the count, $M R I$ magnetic resonance imaging, nraxSpA nonradiographic axial spondyloarthritis, NSAIDs nonsteroidal anti-inflammatory drugs, TNFi tumor necrosis factor inhibitor

patients $(73.6 \%)$ and in a comparable proportion of women vs. men $(72.9 \%$ vs. $74.4 \%$, respectively). Baseline characteristics of these patients (Table 3) were similar to the findings in all nr-axSpA patients starting a TNFi (Table 2). In response/tolerance analyses, an ASAS40 response was achieved by $17 \%$ of women and $38 \%$ of men (OR 0.34; 95\% CI 0.12, 0.93; Table 4). ASAS40 responses were even lower in women than in men after adjustment for baseline differences in BASDAI, MASES, BMI and diagnostic delay (OR 0.19; 95\% CI 0.05, 0.61; Tables 4 and 5). A higher BMI was associated with a lower ASAS40 response (Table 5). In contrast, higher BASDAI levels were associated with a trend for better ASAS40 response. Crude response analyses and adjusted analyses for other outcomes confirmed these results (Table 4). Comparable results were obtained in a sensitivity analysis of the response/tolerance analysis, excluding patients having stopped the TNFi because of other reasons for discontinuation and imputing patients having discontinued the TNFi due to remission as responders (Table 6). All adjusted treatment responses were still significantly lower in women in comparison to men in $\mathrm{nr}-$ axSpA patients still on first TNFi at 1 year (completer analysis; OR 0.25; 95\% CI 0.06, 0.91; Tables 4 and 5).

\section{Discussion}

This real-life cohort of patients with nr-axSpA, with classification performed after central reading of pelvis radiographs, reveals less differences in demographics and clinical manifestations between women and men than previously found for the radiographic subgroup of axSpA. Despite continuous efforts for early diagnosis, diagnostic delay is, however, still considerable in $\mathrm{nr}$ axSpA (approximately 5 years) and significantly longer (>1 year) in women than in men. In contrast to $r-$ axSpA, age at symptom onset in female vs. male patients is comparable in $\mathrm{nr}$-axSpA [29]. Importantly, in contrast to $\mathrm{r}$-axSpA, there were no differences between the genders with regard to important clinical parameters: disease activity as assessed by the ASDAS; the proportion of patients with elevated CRP; the level of CRP elevation; the proportion of patients with sacroiliac joint and spinal MRI inflammation; the presence of peripheral arthritis and dactylitis; functional and mobility impairments as assessed by the BASFI and BASMI, respectively; health-related quality of life; and global assessment of disease by patients or their rheumatologists. Despite these similarities between the genders in nr-axSpA, response to TNFi was significantly lower in women than in men (ASAS40 response: OR 0.19; 95\% CI 0.05, 0.62; $p=0.009$ ). This differences in ASAS40 response between the genders is greater than the one found in $\mathrm{r}-\mathrm{axSpA}$ in our previous report (OR 0.44; 95\% CI 0.21, 0.91; $p=$ 0.03) [18]. The most important difference between men and women in nr-axSpA related to the BASDAI, as a patient-reported disease activity outcome. The amplitude of this difference was slightly lowered by exclusion of $n r-a x S p A$ patients with co-morbid fibromyalgia, which was more commonly seen in women, confirming previous analyses [30-32]. We cannot entirely exclude the possibility that diagnosis of concurrent fibromyalgia might have been missed in some patients, as clinical differentiation between enthesitis and allodynia of fibromyalgia might be challenging in clinical practice. However, our results were adjusted for the remaining differences in BASDAI and MASES. Moreover, a higher prevalence of enthesitis in women compared to men has consistently been shown in the radiographic disease state, not excluding a potential phenotypic distinction between the genders [33].

Less than $10 \%$ of women reached strict treatment response criteria, such as the ASDAS major improvement or remission criteria, while more than $25 \%$ of men with nr-axSpA achieved these responses. Male sex was also identified to be an important predictor of remission in $\mathrm{nr}$-axSpA patients treated with adalimumab in the open- 
Table 2 Characteristics of nr-axSpA patients at initiation of first TNFi treatment after exclusion of patients with co-morbid fibromyalgia

\begin{tabular}{|c|c|c|c|c|}
\hline Parameter & $N, 163$ & Men, $N=78$ & Women, $N=85$ & $p$ \\
\hline Age, years & 163 & $35.6(10.8)$ & $39.1(11.4)$ & 0.10 \\
\hline Age at onset, years & 162 & $27.9(8.6)$ & $28.1(8.5)$ & 0.66 \\
\hline Symptom duration, years & 163 & $7.6(8.8)$ & $10.9(10.8)$ & 0.05 \\
\hline Diagnostic delay, years & 162 & $4.1(7.6)$ & $7.8(9.9)$ & 0.005 \\
\hline HLA-B27 positive, $\%$ & 149 & 75.7 & 68.0 & 0.36 \\
\hline Prior sacroiliitis on MRI, $\%$ & 154 & 70.8 & 68.3 & 0.86 \\
\hline BASDAI & 148 & $5.3(2.0)$ & $6.3(1.6)$ & 0.003 \\
\hline Physician Global Assessment & 155 & $5.0(1.9)$ & $4.8(1.6)$ & 0.63 \\
\hline Patient Global Assessment & 149 & $6.4(2.2)$ & $6.7(2.1)$ & 0.30 \\
\hline ASDAS & 140 & $3.3(1.0)$ & $3.4(0.7)$ & 0.29 \\
\hline ASDAS $>2.1, \%$ & 140 & 83.9 & 96.2 & 0.02 \\
\hline CRP (mg/l), median (IQR) & 154 & $6.0(2.0 ; 12.0)$ & $5.0(3.0 ; 9.0)$ & 0.43 \\
\hline Elevated CRP, \% & 154 & 42.5 & 38.3 & 0.62 \\
\hline BASFI & 148 & $3.6(2.4)$ & $3.8(2.5)$ & 0.54 \\
\hline BASMI & 141 & $1.2(1.1)$ & $1.4(1.2)$ & 0.42 \\
\hline$E Q-5 D$ & 141 & $54.8(22.8)$ & $55.8(18.3)$ & 0.79 \\
\hline Current periph. Arthritis, $\%$ & 159 & 41.6 & 52.4 & 0.20 \\
\hline Number of swollen joints & 155 & $0.7(1.2)$ & $1.3(2.5)$ & 0.32 \\
\hline Current enthesitis, \% & 158 & 80.5 & 85.2 & 0.53 \\
\hline Modified MASES & 157 & $2.3(2.5)$ & $3.9(3.3)$ & 0.002 \\
\hline Dactylitis ever, \% & 161 & 13.2 & 21.2 & 0.21 \\
\hline csDMARDs ever, \% & 163 & 26.9 & 41.2 & 0.07 \\
\hline Taking NSAIDs, \% & 150 & 92.9 & 86.2 & 0.29 \\
\hline Current smoking, \% & 139 & 28.3 & 22.8 & 0.55 \\
\hline Body mass index & 160 & $25.9(4.2)$ & $24.0(4.4)$ & $<0.001$ \\
\hline Type of TNFi, \% & 163 & & & 0.25 \\
\hline - Adalimumab & & 34.6 & 45.9 & \\
\hline - Certolizumab & & 1.3 & 0.0 & \\
\hline - Etanercept & & 19.2 & 15.3 & \\
\hline - Golimumab & & 20.5 & 24.7 & \\
\hline - Infliximab & & 24.4 & 14.1 & \\
\hline
\end{tabular}

Except where indicated otherwise, values are the mean (SD). Data in bold are statistically significant. Patients with co-morbid fibromyalgia were excluded from these analyses. ASDAS Ankylosing Spondylitis Disease Activity Score, BASDAl Bath Ankylosing Spondylitis Disease Activity Index, BASFl Bath Ankylosing Spondylitis Functional Index, BASMI Bath Ankylosing Spondylitis Metrology Index, CRP C-reactive protein levels; CSDMARDs conventional synthetic disease-modifying antirheumatic drugs, EQ-5D EuroQol 5-domains, HLA-B27 human leucocyte antigen B27, MASES Maastricht Ankylosing Spondylitis Enthesitis Score, modification refers to the inclusion of the plantar fascia in the count, nr-axSpA nonradiographic axial spondyloarthritis, NSAIDs nonsteroidal anti-inflammatory drugs, TNFi tumor necrosis factor inhibitor

label phase of a recent trial [27], as well as in a Danish observational study investigating treatment response in AS vs. nr-axSpA after adjustment for sex [8]. Our current study therefore adds to available data to support the claim for future randomized controlled trials in axSpA to be sufficiently powered to detect potential sex differences [33].

Some limitations of our current analyses have to be acknowledged. Concern has arisen that since the introduction of the ASAS axSpA classification criteria misclassification or overtreatment might occur more frequently, particularly in $\mathrm{nr}-\mathrm{axSpA}[34,35]$. There is increasing evidence that several imaging abnormalities might mimic mild sacroiliitis on MRI and some of these are more frequent in women (such as bone more edema following pregnancy or associated with osteitis condensans ilii) [36-38]. We were not able to evaluate the extent of this potential imaging 
Table 3 Characteristics of nr-axSpA patients at initiation of first TNFi treatment with available follow-up visit at 1 year (patients with co-morbid fibromyalgia excluded)

\begin{tabular}{|c|c|c|c|c|c|c|c|c|}
\hline \multirow[t]{2}{*}{ Parameter } & \multicolumn{4}{|c|}{$\begin{array}{l}\text { A. } \mathrm{Nr} \text {-axSpA patients with available follow-up visit } \\
\text { at } 1 \text { year }\end{array}$} & \multicolumn{4}{|c|}{$\begin{array}{l}\text { B. Nr-axSpA patients still on TNFi treatment } \\
\text { at } 1 \text { year }\end{array}$} \\
\hline & $N, 120$ & Men, $N=58$ & Women, $N=62$ & $p$ & $N, 83$ & Men, $N=45$ & Women, $N=38$ & $p$ \\
\hline Age, years & 120 & $36.0(10.8)$ & $38.6(11.4)$ & 0.25 & 83 & $34.6(10.3)$ & $39.2(13.4)$ & 0.16 \\
\hline Age at onset, years & 120 & $27.7(8.4)$ & $27.9(8.2)$ & 0.78 & 83 & $27.4(8.0)$ & $27.4(7.5)$ & 0.89 \\
\hline Symptom duration, years & 120 & $8.3(9.5)$ & $10.7(11.3)$ & 0.27 & 83 & $7.2(7.8)$ & $11.7(12.2)$ & 0.12 \\
\hline Diagnostic delay, years & 120 & $4.7(8.6)$ & $7.3(10.1)$ & 0.03 & 83 & $3.0(5.3)$ & $7.4(10.3)$ & 0.02 \\
\hline HLA-B27 positive, $\%$ & 110 & 79.6 & 73.2 & 0.50 & 78 & 83.3 & 77.8 & 0.58 \\
\hline Prior sacroiliitis on MRI, \% & 112 & 67.9 & 67.8 & 1.00 & 77 & 66.7 & 65.7 & 1.00 \\
\hline BASDAI & 108 & $5.4(2.0)$ & $6.1(1.6)$ & 0.05 & 74 & $5.2(2.0)$ & $5.9(1.6)$ & 0.09 \\
\hline Physician Global Assessment & 115 & $5.1(1.9)$ & $4.8(1.7)$ & 0.54 & 81 & $5.3(2.0)$ & $4.7(1.8)$ & 0.28 \\
\hline Patient Global Assessment & 109 & $6.6(2.2)$ & $6.7(1.9)$ & 1.00 & 75 & $6.5(2.2)$ & $6.4(2.0)$ & 0.89 \\
\hline ASDAS & 100 & $3.4(0.9)$ & $3.4(0.7)$ & 0.63 & 69 & $3.4(0.9)$ & $3.4(0.6)$ & 0.90 \\
\hline ASDAS $>2.1, \%$ & 100 & 88.9 & 94.5 & 0.46 & 69 & 91.7 & 97.0 & 0.62 \\
\hline CRP (mg/l), median (IQR) & 111 & $7.0(2.0 ; 15.0)$ & $7.0(3.0 ; 10.0)$ & 0.63 & 77 & $7.3(3.0 ; 19.5)$ & $7.0(3.5 ; 10.5)$ & 0.37 \\
\hline Elevated CRP, \% & 111 & 47.2 & 43.1 & 0.71 & 77 & 54.8 & 42.9 & 0.36 \\
\hline BASFI & 109 & $3.7(2.4)$ & $3.5(2.4)$ & 0.61 & 75 & $3.5(2.4)$ & $3.2(2.3)$ & 0.53 \\
\hline BASMI & 102 & $1.2(1.1)$ & $1.4(1.2)$ & 0.37 & 70 & $1.1(1.1)$ & $1.2(1.3)$ & 0.88 \\
\hline EQ-5D & 103 & $53.7(22.8)$ & $57.6(17.8)$ & 0.52 & 70 & $55.6(21.7)$ & $59.2(15.7)$ & 0.65 \\
\hline Current periph. arthritis, $\%$ & 116 & 47.4 & 47,5 & 1.00 & 82 & 46.7 & 54.0 & 0.66 \\
\hline Number of swollen joints & 113 & $0.7(1.2)$ & $1.2(2.6)$ & 0.83 & 80 & $0.8(1.3)$ & $1.5(2.9)$ & 0.52 \\
\hline Current enthesitis, \% & 115 & 80.7 & 86.2 & 0.46 & 82 & 80.0 & 86.5 & 0.56 \\
\hline Modified MASES & 114 & $2.4(2.6)$ & $3.7(3.2)$ & 0.02 & 81 & $2.1(2.2)$ & $3.4(2.7)$ & 0.03 \\
\hline Dactylitis ever, \% & 118 & 16.1 & 19.4 & 0.81 & 82 & 11.4 & 21.1 & 0.36 \\
\hline csDMARDs ever, \% & 120 & 31.0 & 40.3 & 0.34 & 83 & 26.7 & 36.8 & 0.35 \\
\hline Taking NSAIDs, \% & 109 & 94.1 & 86.2 & 0.21 & 76 & 100.0 & 85.7 & 0.02 \\
\hline Current smoking, \% & 102 & 28.9 & 15.8 & 0.15 & 68 & 26.5 & 8.8 & 0.11 \\
\hline Body mass index & 120 & $25.9(4.2)$ & $24.0(4.4)$ & 0.002 & 83 & $25.6(4.2)$ & $23.6(4.7)$ & 0.004 \\
\hline Type of TNFi, \% & 120 & & & 0.69 & 83 & & & 0.38 \\
\hline - Adalimumab & & 34.5 & 43.5 & & & 35.6 & 50.0 & \\
\hline - Certolizumab & & 1.7 & 0.0 & & & 2.2 & 0.0 & \\
\hline - Etanercept & & 19.0 & 16.1 & & & 20.0 & 10.5 & \\
\hline - Golimumab & & 22.4 & 24.2 & & & 20.0 & 26.3 & \\
\hline - Infliximab & & 22.4 & 16.1 & & & 22.2 & 13.2 & \\
\hline
\end{tabular}

A is the characteristics of patients starting TNFi included in the response/tolerance analyses: response in patients with available outcome at 1 year, patients having discontinued the first TNFi in the meantime being considered non-responders. B is the characteristics of patients starting TNFi included in the completer analyses at 1 year. Except where indicated otherwise, values are the mean (SD). Data in bold are statistically significant. Patients with co-morbid fibromyalgia were excluded from these analyses. ASDAS Ankylosing Spondylitis Disease Activity Score, BASDAI Bath Ankylosing Spondylitis Disease Activity Index, BASFI Bath Ankylosing Spondylitis Functional Index, BASMI Bath Ankylosing Spondylitis Metrology Index, CRP C-reactive protein levels, CSDMARDs conventional synthetic disease-modifying anti-rheumatic drugs, EQ-5D EuroQol 5-domains, HLA-B27 human leucocyte antigen B27, MASES Maastricht Ankylosing Spondylitis Enthesitis Score, modification refers to the inclusion of the plantar fascia in the count, $n r-a x S p A$ nonradiographic axial spondyloarthritis, NSAIDs nonsteroidal antiinflammatory drugs, TNFi tumor necrosis factor inhibitor

misinterpretation, as MRIs were not available for central scoring. This also impeded the evaluation of potential sex differences regarding the extent and the intensity of sacroiliac joint inflammation in $\mathrm{nr}$-axSpA $[39,40]$. With regard to potential misdiagnosis of fibromyalgia as axSpA, it is important to note that patients with fibromyalgia rarely fulfill classification criteria for axSpA, as has recently been demonstrated $[41,42]$. We have excluded axSpA patients with concurrent fibromyalgia from the treatment effectiveness 
Table 4 Clinical outcome of women versus men with nr-axSpA after 1 year of treatment with a first TNF inhibitor

\begin{tabular}{|c|c|c|c|c|c|c|c|c|c|c|c|}
\hline \multirow[t]{2}{*}{ Type of analysis } & \multirow[t]{2}{*}{ Outcome } & \multicolumn{6}{|c|}{ Unadjusted analyses } & \multicolumn{4}{|c|}{ Adjusted analyses $^{\#}$} \\
\hline & & $N$ & Women \% & Men \% & OR & $95 \% \mathrm{Cl}$ & $p$ & $N$ & OR & $95 \% \mathrm{Cl}$ & $p$ \\
\hline \multirow[t]{7}{*}{ Response/tolerance* } & ASAS20 & 99 & 27 & 57 & 0.28 & $0.11 ; 0.68$ & 0.002 & 93 & 0.16 & $0.04 ; 0.50$ & 0.003 \\
\hline & ASAS40 & 99 & 17 & 38 & 0.34 & $0.12 ; 0.93$ & 0.02 & 93 & 0.19 & $0.05 ; 0.62$ & 0.009 \\
\hline & BASDAI50 & 98 & 23 & 50 & 0.30 & $0.11 ; 0.77$ & 0.007 & 93 & 0.19 & $0.05 ; 0.58$ & 0.005 \\
\hline & ASDAS improvement $\geq 1.1$ & 84 & 28 & 58 & 0.29 & $0.10 ; 0.78$ & 0.008 & 82 & 0.26 & $0.08 ; 0.75$ & 0.02 \\
\hline & ASDAS $<2.1$ & 93 & 27 & 49 & 0.39 & $0.15 ; 1.00$ & 0.03 & 86 & 0.18 & $0.04 ; 0.65$ & 0.01 \\
\hline & ASDAS improvement $\geq 2$ & 84 & 4 & 26 & 0.13 & $0.01 ; 0.68$ & 0.005 & 82 & 0.04 & $0.00 ; 0.27$ & 0.003 \\
\hline & ASDAS $<1.3$ & 93 & 8 & 29 & 0.23 & $0.05 ; 0.82$ & 0.01 & 86 & 0.07 & $0.01 ; 0.39$ & 0.005 \\
\hline \multirow[t]{7}{*}{ Completer** } & ASAS20 & 68 & 45 & 73 & 0.31 & $0.10 ; 0.94$ & 0.03 & 66 & 0.15 & $0.03 ; 0.60$ & 0.01 \\
\hline & ASAS40 & 68 & 29 & 49 & 0.44 & $0.14 ; 1.31$ & 0.14 & 66 & 0.25 & $0.06 ; 0.91$ & 0.04 \\
\hline & BASDAI50 & 67 & 39 & 64 & 0.36 & $0.12 ; 1.07$ & 0.05 & 66 & 0.20 & $0.05 ; 0.75$ & 0.02 \\
\hline & ASDAS improvement $\geq 1.1$ & 61 & 46 & 67 & 0.44 & $0.14 ; 1.38$ & 0.13 & 60 & 0.36 & $0.09 ; 1.29$ & 0.13 \\
\hline & ASDAS $<2.1$ & 67 & 43 & 59 & 0.53 & $0.18 ; 1.54$ & 0.22 & 63 & 0.28 & $0.06 ; 1.12$ & 0.08 \\
\hline & ASDAS improvement $\geq 2$ & 61 & 7 & 30 & 0.18 & $0.02 ; 0.98$ & 0.03 & 60 & 0.05 & $0.00 ; 0.38$ & 0.01 \\
\hline & ASDAS $<1.3$ & 67 & 13 & 35 & 0.29 & $0.06 ; 1.11$ & 0.05 & 63 & 0.08 & $0.01 ; 0.47$ & 0.01 \\
\hline
\end{tabular}

*Response in patients with available outcome at 1 year, patients having discontinued the first TNFi in the meantime being considered non-responders. **Response in patients still on their first TNFi at 1 year. Patients with co-morbid fibromyalgia were excluded from these analyses. "Adjustment for diagnostic delay, MASES, BASDAI and BMI. ASAS20 and ASAS40 20\% and 40\% improvement according to the ASAS criteria, respectively; ASDAS Ankylosing Spondylitis Disease Activity Score; BASDAI50 50\% improvement in the BASDAl; nr-axSpA nonradiographic axial spondyloarthritis; TNF tumor necrosis factor

analyses, if its presence was either reported at start of treatment or at any time-point during follow-up. However, we might have missed some patients, as the screening for fibromyalgia was based on the expert opinion of the treating rheumatologist reported on a comorbidity questionnaire and not through fulfillment of classification criteria for fibromyalgia or via the use of a standardized fibromyalgia questionnaire. The comorbidity form was available in $62 \%$ of the population as the rheumatologist was led through it in the online database before being able to enter the findings of the clinical examination to help with its systematic completion. Given the fact that patients treated with biologics are preferentially included in
SCQM, we expected a lower proportion of patients with fibromyalgia in comparison to other axSpA studies, assuming that rheumatologists might be reluctant to install biologics in axSpA patients diagnosed with concurrent fibromyalgia.

We have found a lower proportion of HLA-B27 in women as compared to men, as has also been reported for the radiographic disease form in SCQM [18] as well as in the US PSOAS cohort [12]. While genotypic differences between genders cannot be entirely excluded, this finding might alternatively point to the possibility of a higher misclassification rate in women. We have not adjusted our response analyses for HLA-B27 as the respective proportions of positivity in men and women

Table 5 Adjusted ASAS40 response of women versus men after 1 year of treatment with a first TNF inhibitor

\begin{tabular}{|c|c|c|c|c|c|c|}
\hline \multirow[t]{2}{*}{ Variable } & \multicolumn{3}{|c|}{ A. Response/tolerance analysis } & \multicolumn{3}{|c|}{ B. Completer analysis } \\
\hline & $\overline{\mathrm{OR}}$ & $95 \% \mathrm{Cl}$ & $p$ & $\overline{O R}$ & $95 \% \mathrm{Cl}$ & $p$ \\
\hline Female vs. male & 0.19 & $0.05 ; 0.62$ & 0.009 & 0.25 & $0.06 ; 0.91$ & 0.04 \\
\hline Diagnostic delay & 0.97 & $0.91 ; 1.03$ & 0.41 & 0.98 & $0.90 ; 1.05$ & 0.66 \\
\hline Modified MASES & 0.82 & $0.61 ; 1.05$ & 0.14 & 0.77 & $0.56 ; 1.02$ & 0.08 \\
\hline BASDAI & 1.24 & $0.91 ; 1.75$ & 0.18 & 1.41 & $1.00 ; 2.08$ & 0.06 \\
\hline BMI & 0.78 & $0.64 ; 0.92$ & 0.008 & 0.82 & $0.66 ; 0.97$ & 0.04 \\
\hline
\end{tabular}

A is the ASAS40 response in patients with available outcome at 1 year, patients having discontinued the first TNFi in the meantime being considered nonresponders. B is the ASAS40 response in patients still treated with the first TNF inhibitor at 1 year. Patients with co-morbid fibromyalgia were excluded from both analyses. ASAS40 40\% improvement according to the Assessment in SpondyloArthritis International Society criteria, BASDAI Bath Ankylosing Spondylitis Disease Activity Index, BMI body mass index; $\mathrm{Cl}$ confidence interval; MASES Maastricht Ankylosing Spondylitis Enthesitis Score, modification refers to the inclusion of the plantar fascia in the count, $O R$ odds ratio 
Table 6 Sensitivity analysis: response/tolerance analysis at 1 year excluding patients having stopped TNFi due to other reasons than ineffectiveness and adverse events and imputing patients having discontinued the TNFi because of remission as being responders

\begin{tabular}{lllll}
\hline Outcome & $\boldsymbol{N}$ & OR & $\mathbf{9 5 \%} \mathbf{C l}$ & $\boldsymbol{p}$ \\
\hline ASAS20 & 89 & 0.20 & $0.06 ; 0.62$ & 0.008 \\
ASAS40 & 89 & 0.25 & $0.07 ; 0.78$ & 0.02 \\
BASDAI50 & 89 & 0.24 & $0.07 ; 0.72$ & 0.01 \\
ASDAS improvement $\geq \mathbf{1 . 1}$ & 78 & 0.32 & $0.10 ; 0.93$ & 0.04 \\
ASDAS $<\mathbf{2 . 1}$ & 82 & 0.26 & $0.06 ; 0.91$ & 0.04 \\
ASDAS improvement $\geq \mathbf{2}$ & 78 & 0.08 & $0.01 ; 0.43$ & 0.006 \\
ASDAS $<\mathbf{1 . 3}$ & 82 & 0.14 & $0.02 ; 0.62$ & 0.02
\end{tabular}

Analyses are adjusted for diagnostic delay, MASES, BASDAl, and BMI. ASAS20 and ASAS40 20\% and 40\% improvement according to the ASAS criteria, respectively; ASDAS Ankylosing Spondylitis Disease Activity Score; BASDAI50 $50 \%$ improvement in the BASDAl; $n r-a x S p A$ nonradiographic axial spondyloarthritis; TNF tumor necrosis factor

were comparable at start of treatment. This would indicate that rheumatologists might have been more confident of the axSpA diagnosis in women in the presence of HLA-B27 positivity in order to start TNFi treatment. The proportion of patients with a positive family history of spondyloarthritis was higher in women and this difference might potentially involve recall bias.

\section{Conclusion}

Despite only few sex differences in baseline characteristics of patients with nr-axSpA, a disease subgroup known for its balanced sex ratio, response to treatment with TNFi was significantly lower in women than in men.

\section{Abbreviations}

ASAS: Assessment in SpondyloArthritis international Society; ASAS40: 40\% improvement in the ASAS criteria; ASDAS: Ankylosing Spondylitis Disease Activity Score; axSpA: Axial spondyloarthritis; BASDAI: Bath Ankylosing Spondylitis Disease Activity Index; BASFI: Bath Ankylosing Spondylitis Functional Index; BASMI: Bath Ankylosing Spondylitis Metrology Index; BMI: Body mass index; bDMARD: Biologic disease-modifying anti-rheumatic drug; Cl: Confidence interval; CRP: C-reactive protein; HLA-B27: Human leucocyte antigen B27; MASES: Maastricht Ankylosing Spondylitis Enthesitis Score; MRI: Magnetic resonance imaging; nr-axSpA: Nonradiographic axial spondyloarthritis; NSAID: Nonsteroidal anti-inflammatory drug; OR: Odds ratio; r-axSpA: Radiographic axial spondyloarthritis; SCQM: Swiss Clinical Quality Management; TNFi: Tumor necrosis factor inhibitor

\section{Acknowledgements}

We thank all rheumatologists and their patients for participation to SCQM. The entire SCQM staff was instrumental for data management and support. A list of rheumatology practices and hospitals that are contributing to the SCQM registries can be found on http://www.scam.ch/institutions.

\section{Authors' contributions}

RN performed research, analyzed data, and wrote the manuscript. AC designed the study. MH and AS supervised the implementation of the statistical analyses. All investigators substantially contributed to the acquisition, analysis, or interpretation of data. All coauthors revised the manuscript critically for important intellectual content. All authors read and approved the final manuscript.

\section{Funding}

This study was funded by the Stiftung für Rheumaforschung, Zurich, Switzerland. The study sponsors had no role in the study design or in the collection, analysis or interpretation of the data, the writing of the manuscript, or the decision to submit the manuscript for publication.

\section{Availability of data and materials}

The data sets analyzed during the current study are available from the corresponding author on reasonable request.

\section{Ethics approval and consent to participate}

The Ethics committee of the Canton of Zurich (KEK-ZH-Nr. 2014-0439) approved the study. Written informed consent was obtained from all patients prior to inclusion into SCQM.

\section{Consent for publication}

Not applicable.

\section{Competing interests}

The SCQM Foundation is supported by the Swiss Society of Rheumatology and by AbbVie, Celgene, Lilly, Merck Sharp \& Dohme, Novartis, Pfizer, Roche, Samsung, Sandoz, Sanofi, and UCB and has received project-based financial supports from the Arco Foundation, Switzerland, as well as from the Swiss Balgrist Society, Switzerland. AC has received consulting and/or speaking fees from AbbVie, Bristol-Myers Squibb, Celgene, Eli Lilly, Merck Sharp \& Dohme, Novartis, and Pfizer. MJN has received consulting and/or speaking fees from Abbvie, Eli Lilly, Novartis, and Pfizer. RN, MH, RM, KB, PE, KN, and AS declare that they have no competing interest. No non-financial conflicts of interest exist for any of the authors.

\section{Author details}

'Department of Rheumatology, Zurich University Hospital, Gloriastrasse 25, $\mathrm{CH}-8091$ Zurich, Switzerland. ${ }^{2}$ Swiss Clinical Quality Management Foundation, Statistics Group, Zurich, Switzerland. ${ }^{3}$ Rheumatology Practice, Basel, Switzerland. ${ }^{4}$ School of Health Professions, Institute of Physiotherapy, Zurich University of Applied Sciences, Winterthur, Switzerland. ${ }^{5}$ Department of Rheumatology, University Hospital, Geneva, Switzerland.

Received: 2 April 2020 Accepted: 2 October 2020

Published online: 09 October 2020

\section{References}

1. Rudwaleit M, van der Heijde D, Landewe R, Listing J, Akkoc N, Brandt J, et al. The development of Assessment of SpondyloArthritis international Society classification criteria for axial spondyloarthritis (part II): validation and final selection. Ann Rheum Dis. 2009:68:777-83.

2. van der Linden $\mathrm{S}$, Valkenburg HA, Cats A. Evaluation of diagnostic criteria for ankylosing spondylitis. A proposal for modification of the New York criteria. Arthritis Rheum. 1984;27:361-8.

3. Deodhar A, Reveille JD, van den Bosch F, Braun J, Burgos-Vargas R, Caplan L, et al. The concept of axial spondyloarthritis: joint statement of the spondyloarthritis research and treatment network and the Assessment of SpondyloArthritis international Society in response to the US Food and Drug Administration's comments and concerns. Arthritis Rheumatol. 2014; 66:2649-56.

4. Rudwaleit M, Haibel H, Baraliakos X, Listing J, Marker-Hermann E, Zeidler $H$, et al. The early disease stage in axial spondylarthritis: results from the German Spondyloarthritis inception cohort. Arthritis Rheum. 2009;60:717-27.

5. Kiltz U, Baraliakos $X$, Karakostas $P$, Igelmann $M$, Kalthoff $L$, Klink $C$, et al. Do patients with non-radiographic axial spondyloarthritis differ from patients with ankylosing spondylitis? Arthritis Care Res (Hoboken). 2012;64:1415-22.

6. Ciurea A, Scherer A, Exer P, Bernhard J, Dudler J, Beyeler B, et al. Tumor necrosis factor-alpha inhibition in radiographic and non-radiographic axial spondyloarthritis: results from a large observational cohort. Arthritis Rheum. 2013;65:3096-106

7. Wallis D, Haroon N, Ayearst R, Carty A, Inman RD. Ankylosing spondylitis and nonradiographic axial spondyloarthritis: part of a common spectrum or distinct diseases? J Rheumatol. 2013:40:2038-41.

8. Glintborg B, Sorensen IJ, Ostergaard M, Dreyer L, Mohamoud AA, Krogh NS, et al. Ankylosing spondylitis versus nonradiographic axial spondyloarthritis: comparison of tumor necrosis factor inhibitor effectiveness and effect of 
HLA-B27 status. An observational cohort study from the Nationwide DANBIO registry. J Rheumatol. 2017;44:59-69.

9. Mease PJ, Heijde DV, Karki C, Palmer JB, Liu M, Pandurengan R, et al. Characterization of patients with ankylosing spondylitis and nonradiographic axial spondyloarthritis in the US-based corrona registry. Arthritis Care Res (Hoboken). 2018;70:1661-70.

10. Poddubnyy D, Sieper J. Similarities and differences between nonradiographic and radiographic axial spondyloarthritis: a clinical, epidemiological and therapeutic assessment. Curr Opin Rheumatol. 2014;26: 377-83.

11. Lockwood MM, Gensler LS. Nonradiographic axial spondyloarthritis. Best Pract Res Clin Rheumatol. 2017;31:816-29.

12. Lee W, Reveille JD, Davis JC Jr, Learch TJ, Ward MM, Weisman MH. Are there gender differences in severity of ankylosing spondylitis? Results from the PSOAS cohort. Ann Rheum Dis. 2007:66:633-8.

13. Roussou E, Sultana S. Spondyloarthritis in women: differences in disease onset, clinical presentation, and Bath Ankylosing Spondylitis Disease Activity and Functional indices (BASDAI and BASFI) between men and women with spondyloarthritides. Clin Rheumatol. 2011;30:121-7.

14. Slobodin G, Reyhan I, Avshovich N, Balbir-Gurman A, Boulman N, Elias M, et al. Recently diagnosed axial spondyloarthritis: gender differences and factors related to delay in diagnosis. Clin Rheumatol. 2011;30:1075-80.

15. Ortega Castro R, Font Ugalde P, Castro Villegas MC, Calvo Gutierrez J, Munoz Gomariz E, Zarco Montejo P, et al. Different clinical expression of patients with ankylosing spondylitis according to gender in relation to time since onset of disease. Data from REGISPONSER. Reumatol Clin. 2013;9:221-5.

16. de Carvalho HM, Bortoluzzo AB, Goncalves CR, da Silva JA, Ximenes AC, Bertolo MB, et al. Gender characterization in a large series of Brazilian patients with spondyloarthritis. Clin Rheumatol. 2012;31:687-95.

17. van der Horst-Bruinsma IE, Zack DJ, Szumski A, Koenig AS. Female patients with ankylosing spondylitis: analysis of the impact of gender across treatment studies. Ann Rheum Dis. 2013:72:1221-4.

18. Hebeisen M, Neuenschwander R, Scherer A, Exer P, Weber U, Tamborrini G, et al. Response to tumor necrosis factor inhibition in male and female patients with ankylosing spondylitis: data from a Swiss cohort. J Rheumatol. 2018:45:506-12.

19. Lubrano E, Perrotta FM, Manara M, D'Angelo S, Addimanda O, Ramonda R, et al. The sex influence on response to tumor necrosis factor-alpha inhibitors and remission in axial spondyloarthritis. J Rheumatol. 2018;45:195-201.

20. Tournadre A, Pereira B, Lhoste A, Dubost J, Ristori J, Claudepierre P, et al. Differences between women and men with recent onset axial spondyloarthritis: results from the DESIR cohort. Arthritis Care Res (Hoboken). 2013;59:449-54.

21. Sieper J, van der Heijde D, Dougados M, Mease PJ, Maksymowych WP Brown MA, et al. Efficacy and safety of adalimumab in patients with nonradiographic axial spondyloarthritis: results of a randomised placebocontrolled trial (ABILITY-1). Ann Rheum Dis. 2013;72:815-22.

22. Landewe R, Braun J, Deodhar A, Dougados M, Maksymowych WP, Mease PJ, et al. Efficacy of certolizumab pegol on signs and symptoms of axial spondyloarthritis including ankylosing spondylitis: 24-week results of a double-blind randomised placebo-controlled phase 3 study. Ann Rheum Dis. 2014;73:39-47.

23. Sieper J, van der Heijde D, Dougados M, Maksymowych WP, Scott BB, Boice JA, et al. A randomized, double-blind, placebo-controlled, sixteen-week study of subcutaneous golimumab in patients with active nonradiographic axial spondyloarthritis. Arthritis Rheumatol. 2015;67:2702-12.

24. Maksymowych WP, Dougados M, van der Heijde D, Sieper J, Braun J, Citera $\mathrm{G}$, et al. Clinical and MRI responses to etanercept in early non-radiographic axial spondyloarthritis: 48-week results from the EMBARK study. Ann Rheum Dis. 2016;75:1328-35

25. van der Heijde D, Ramiro S, Landewe R, Baraliakos X, Van den Bosch F, Sepriano A, et al. 2016 update of the ASAS-EULAR management recommendations for axial spondyloarthritis. Ann Rheum Dis. 2017;76:978-91.

26. Ward MM, Deodhar A, Gensler LS, Dubreuil M, Yu D, Khan MA, et al. 2019 update of the American College of Rheumatology/Spondylitis Association of America/Spondyloarthritis Research and Treatment Network recommendations for the treatment of ankylosing spondylitis and nonradiographic axial spondyloarthritis. Arthritis Care Res (Hoboken). 2019; 71:1285-99.

27. Sieper J, Landewe R, Magrey M, Anderson JK, Zhong S, Wang X, et al. Predictors of remission in patients with non-radiographic axial spondyloarthritis receiving open-label adalimumab in the ABILITY-3 study. RMD Open. 2019;5:e000917.

28. Sieper J, Rudwaleit M, Baraliakos X, Brandt J, Braun J, Burgos-Vargas R, et al. The Assessment of SpondyloArthritis international Society (ASAS) handbook: a guide to assess spondyloarthritis. Ann Rheum Dis. 2009;68(Suppl 2):ii1-44.

29. Ciurea A, Scherer A, Weber U, Neuenschwander R, Tamborrini G, Exer P, et al. Age at symptom onset in ankylosing spondylitis: is there a gender difference? Ann Rheum Dis. 2014;73:1908-10.

30. Macfarlane GJ, Barnish MS, Pathan E, Martin KR, Haywood KL, Siebert S, et al. Co-occurrence and characteristics of patients with axial spondyloarthritis who meet criteria forffibromyalgia: results from a UK national register. Arthritis Rheumatol. 2017;69:2144-50.

31. Swinnen TW, Westhovens R, Dankaerts W, de Vlam K. Widespread pain in axial spondyloarthritis: clinical importance and gender differences. Arthritis Res Ther. 2018:20(1):156.

32. Mogard E, Bremander A, Lindqvist E, Bergman S. Prevalence of chronic widespread pain in a population-based cohort of patients with spondyloarthritis - a cross-sectional study. BMC Rheumatol. 2018;2:11.

33. Rusman T, van Vollenhoven RF, van der Horst-Bruinsma IE. Gender differences in axial spondyloarthritis: women are not so lucky. Curr Rheumatol Rep. 2018;20:35.

34. Nieto RE, Plasencia Rodriguez C, Peiteado Lopez D, Villalba Yllan A, Balsa Criado A, Navarro-Compan V. Are we treating women patients with real axial spondyloarthritis? Semin Arthritis Rheum. 2019. https://doi.org/10.1016/ j.semarthrit.2019.11.011 (Epub ahead of print).

35. Moreno M, Gratacos J, Navarro-Compan V, de Miquel E, Font $\mathrm{P}$, Clavaguera $T$, et al. Should over-treatment of axial spondyloarthritis with biologics remain a concern after the issue of the new ASAS criteria? Data from REGI SPONSERBIO (Spanish Register of Biological Therapy in Spondyloarthritides). Clin Exp Rheumatol. 2018;36:1038-42.

36. de Winter J, de Hooge M, van de Sande M, de Jong H, van Hoeven L, de Koning $A$, et al. Magnetic resonance imaging of the sacroiliac joints indicating aacroiliitis according to the Assessment of SpondyloArthritis international Society definition in healthy individuals, runners, and women with postpartum Back pain. Arthritis Rheumatol. 2018;70:1042-8.

37. Weber U, Jurik AG, Zejden A, Larsen E, Jorgensen SH, Rufibach K, et al. Frequency and anatomic distribution of magnetic resonance imaging features in the sacroiliac joints of young athletes: exploring "background noise" toward a data-driven definition of sacroiliitis in early spondyloarthritis. Arthritis Rheumatol. 2018;70:736-45.

38. Agten CA, Zubler V, Zanetti M, Binkert CA, Kolokythas O, Prentl E, et al. Postpartum bone marrow edema at the sacroiliac joints may mimic sacroiliitis of axial spondyloarthritis on MRI. AJR Am J Roentgenol. 2018;211: 1306-12.

39. van Onna M, Jurik AG, van der Heijde D, van Tubergen A, HeuftDorenbosch L, Landewe R. HLA-B27 and gender independently determine the likelihood of a positive MRI of the sacroiliac joints in patients with early inflammatory back pain: a 2-year MRI follow-up study. Ann Rheum Dis. 2011;70:1981-5.

40. Navarro-Compan V, Ramiro S, Landewe R, Dougados M, Miceli-Richard C, Richette $P$, et al. Disease activity is longitudinally related to sacroiliac inflammation on MRI in male patients with axial spondyloarthritis: 2-years of the DESIR cohort. Ann Rheum Dis. 2016;75:874-8.

41. Baraliakos $X$, Regel A, Kiltz U, Menne HJ, Dybowki F, Igelmann M, et al. Patients with fibromyalgia rarely fulfil classification criteria for axial spondyloarthritis. Rheumatology (Oxford). 2018;57:1541-7.

42. Rudwaleit M. Fibromyalgia is not axial spondyloarthritis. Rheumatology (Oxford). 2018;57:1510-2.

\section{Publisher's Note}

Springer Nature remains neutral with regard to jurisdictional claims in published maps and institutional affiliations. 